\title{
Influences on Swedish schoolchildren's dietary selection: focus on fat and fibre at breakfast
}

\section{Christina Berg}

\section{Introduction}

If dietary interventions are to be effective, more research is needed to provide knowledge about determinants of food choice and about how to effect change in those determinants. This thesis focuses on the first of these issues. Because food choice is influenced by a variety of factors in a dynamic and complex interaction, it can also be examined and understood from many different perspectives. A cognitive angle of approach is adopted in this thesis. Independently of factors (genetic, environmental and cognitive) influencing food preferences and dietary selection, these influences may be reflected in individuals' perceptions. Therefore, studying relationships between people's food choice and their beliefs and attitudes may help us to understand the variation in food selection within a population.

One important aim of the Swedish Action Programme for Nutrition is to increase the consumption of dietary fibre and decrease fat intake. The currently available extensive range of fat-reduced and fibre-enriched foods makes these dietary practices possible, but also makes the selection of a health-promoting diet more complex. This thesis aims to contribute to the understanding of psychosocial influences on schoolchildren's food choice, paying specific attention to fat and fibre content. The focus was on breakfast because typical Swedish breakfast foods are important sources of fat and fibre, each food type available in a number of alternatives with varying fat and fibre content. Furthermore, the Swedish breakfast is also generally a meal varying relatively little from day to day.

\section{Subjects and methods}

The Theory of Planned Behaviour formed the theoretical basis of the studies. Food choices and perceptions were studied by means of questionnaires, food records and interviews. The study population consisted of all pupils in grade 5 (age $\sim 11$ years), 7 (age $\sim 13$ years) and 9 (age $\sim 15$ years) in Mölndal municipality, Sweden $(n=1730)$. U sable questionnaires were completed by 1584 participants (92\%). Acceptable breakfast food records were completed by 1162 children, and 1096 children $(63 \%)$ completed both the questionnaire and the food record. Individual interviews were conducted with approximately $10 \%$ of the $173011-15$ year-olds during school hours. Of the eligible 184 subjects, three declined to participate. A picturesort interview technique, the stacking box methodology, was used to describe perceptions, knowledge and habitual choices (Fig. 1). This interview technique was developed by Jonsson and colleagues.

\section{Results and discussion}

\section{Food choice}

The examined foods were commonly and frequently consumed for breakfast. Reduced-fat choices of milk and spread were common, although

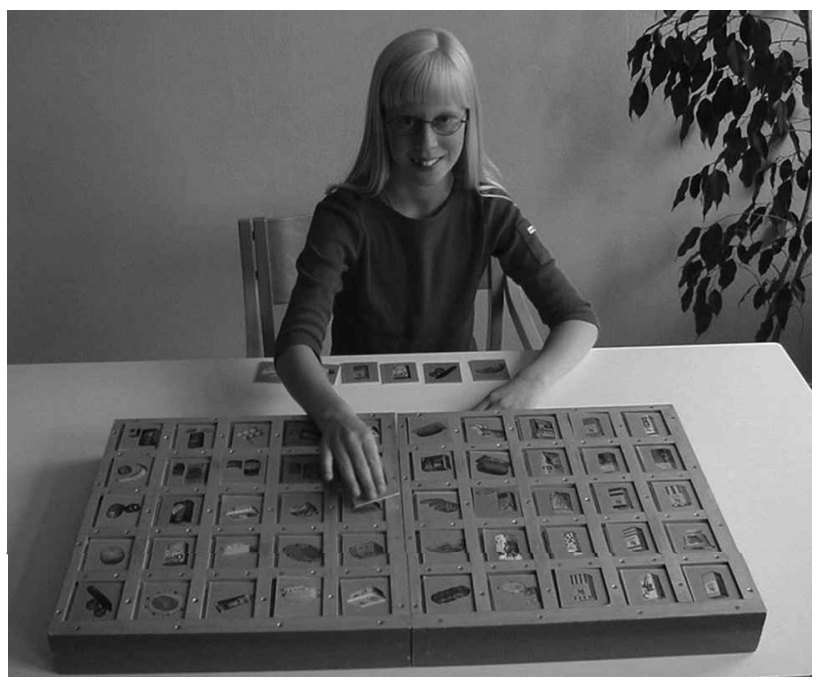

Fig. 1. The stacking box. 
a considerable proportion of the children consumed full-fat alternatives. Regarding the consumption of bread and cereals, the low-fibre alternatives dominated. Thus, 11-15-year-olds have the potential to choose foods containing more fibre and less fat for breakfast.

\section{Attitudes, beliefs and knowledge}

This study demonstrated that 11-15-year-olds' food choices were related to their attitudes and beliefs. Attitudes and food choice were related not only to taste perceptions but also to health and weight concerns. Furthermore, in contrast to several other studies, the results show some positive relationships between dietary knowledge and food choice. Specifically, the choice of high-fibre products was associated with knowledge of fibre sources, and the choice of fat-reduced milk products was associated with a positive attitude towards limited fat intake. In general, the results suggest that consumption of low-fat products may be impeded by health beliefs, while taste appears to be a barrier to the consumption of high-fibre products. Most of the schoolchildren believed that high-fibre products are healthy, but they preferred the taste of low-fibre alternatives. In contrast, they considered their usual milk choice to be healthy and tasty irrespective of type. Thus, strong relationships were observed between taste and health perceptions and choice of milk, and weaker associations and more conflicting perceptions were observed for bread and breakfast cereals.

\section{Social norms}

The results suggest that the 11-15-year-olds were influenced by parental norms in their breakfast choices. It seemed that the parents influenced their children's choice both by direct encouragement and by acting as models. Both injunctive (social approval by others) and descriptive norms (perceptions of how others behave) supported consumption of bread and breakfast cereals with more fibre than in habitually consumed products. Regarding milk and spread, the children chose according to their perceptions of parents' wishes. Thus, injunctive norms did not support a change towards low-fat products among those who did not already consume such products. However, parents' milk choice might induce the children to consume low-fat milk, since they perceived that their mothers and fathers used milk with a lower fat content than in the milk they usually consumed themselves.

\section{Control of consumption}

The results suggest that the 11-15-year-olds did not have complete control over what they consumed for breakfast, but that their breakfast choices were, to a great extent, in accordance with their preferences. Parents' influence on their children's choices by controlling the availability of foods was demonstrated by the children's own stated reasons for breakfast choices and for not consuming preferred foods. In particular, the choice of spread was reported to be determined by availability. However, even if the results suggest that the parents influenced their children's consumption through control over access to food, the children tended not to be restricted to a consumption of high-fibre or low-fat foods.

\section{Limitations and strength}

Food choice must be studied from multiple perspectives and the Theory of Planned Behaviour is one of many theories that can serve as a useful framework when investigating food choice from a cognitive perspective. However, the application of this highly theoretical model to complex behaviours is, unfortunately, associated with some problems in measurement and analysis. In the interview study, the concept of the Theory of Planned Behaviour was adopted as a theoretical framework, but an alternative operationalization of the model was applied. The stacking box interview technique appears to have some advantages over questionnaire studies based on the Theory of Planned Behaviour, and these two applied research approaches complement each other since they are distinguished by specific limitations in many aspects.

Two sources of bias were observed in the food record survey. Non-participants differed significantly from participants, and a decline in recorded foods during the recording period was observed. It is even more likely that such biases are present in other dietary surveys with estimated or weighed records including all meals. Thus, it is of great importance to take such biases into consideration in the design, analysis and interpretation of dietary surveys.

\section{Conclusions}

\section{Practical}

- Actions aiming to influence schoolchildren's breakfast food choices should be addressed both 
to children and to their parents. This applies to teenagers as well as younger children.

- Although it is usually believed that dietary knowledge does not influence dietary behaviour, the results suggest that schoolchildren's breakfast choices are directly associated with their dietary knowledge. Knowledge appears both to motivate and to facilitate "healthier" choices.

- There is a need for increased public knowledge about healthy food alternatives for schoolchildren, particularly regarding alternatives varying in fat content and fat quality.

- In the case of milk choices, children did not show any ambivalence. Thus, a child is likely to prefer the milk that she or he perceives as healthiest, regardless of whether it is low fat or high fat.

- Schoolchildren's consumption of high-fibre products is limited by the fact that they do not find them palatable, but may be increased by altering the taste properties of the foods or by influencing liking for these foods.

\section{Theoretical}

- Errors will always be present in dietary surveys, and should be taken into consideration in the design, analysis and interpretation of these studies.

- The Theory of Planned Behaviour can serve as a useful framework when examining food choice, but the operationalization of the model is associated with some problems. The stacking box interview technique represents a viable alternative to the usual application.
- It is important to investigate descriptive norms in addition to injunctive norms in situations where people serving as models may advocate one thing and do something else themselves. The present results suggest that both descriptive and injunctive norms are important for children's food choices.

\section{Articles in the thesis}

1. Berg C, Jonsson I, Conner MT, Lissner L. Sources of bias in a dietary survey of children. Eur J Clin Nutr 1998; 52: 663-7.

2. Berg C, Jonsson I, Conner M. Understanding choice of milk and bread for breakfast among Swedish children aged 11-15 years: an application of the Theory of Planned Behaviour. Appetite 2000; 34: 5-19.

3. Berg MC, Jonsson I, Conner MT, Lissner L. Relation between breakfast food choices and knowledge of dietary fat and fiber among Swedish schoolchildren. J Adolesc Health 2002; 31: 199-207.

4. Berg C, Jonsson I, Conner M, Lissner L. Perceptions and reasons for choice of fat- and fibre-containing foods by Swedish schoolchildren. Appetite (In press).

The article is based on the author's thesis, which was conducted in collaboration between the Department of Home Economics and the Department of Primary Health Care, both at Göteborg University, Sweden. Defended on September 13, 2002. ISBN: 91-7346-436-8. Distribution: Acta Universitatis Gothoburgensis

Christina Berg
Department of Home Economics
Göteborg University
Box 12204
SE-402 40 Göteborg
Sweden
E-mail: Christina.berg@ped.gu.se

